\title{
Diazotrophic Macroalgal Associations With Living and Decomposing Sargassum
}

\author{
Yubin Raut*, Michael Morando and Douglas G. Capone \\ Marine and Environmental Biology, University of Southern California, Los Angeles, CA, United States
}

Despite several studies reporting diazotrophic macroalgal associations (DMAs), biological nitrogen fixation (BNF) is still largely overlooked as a potential source of nitrogen $(\mathrm{N})$ for macroalgal productivity. We investigated the role of BNF, via the acetylene reduction method, throughout different life stages of the invasive macroalga, Sargassum horneri, in its non-native Southern California coastal ecosystem. Throughout most of its life cycle, BNF rates were not detectable or yielded insignificant amounts of fixed $\mathrm{N}$ to support $\mathrm{S}$. horneri productivity. However, during late summer when nutrient

OPEN ACCESS

Edited by: Mar Benavides, Institut de Recherche pour le Développement (IRD), France

Reviewed by:

Carolin Regina Löscher University of Southern Denmark,

Denmark

Ulisse Cardini,

Stazione Zoologica Anton Dohrn, Italy

${ }^{*}$ Correspondence: Yubin Raut yubinrau@usc.edu

Specialty section: This article was submitted to Aquatic Microbiology, a section of the journal

Frontiers in Microbiology

Received: 09 October 2018 Accepted: 03 December 2018 Published: 18 December 2018

Citation:

Raut $Y$, Morando $M$ and Capone DG (2018) Diazotrophic Macroalgal Associations With Living and Decomposing Sargassum.

Front. Microbiol. 9:3127. doi: 10.3389/fmicb.2018.03127 concentrations are usually at their minimum, BNF associated with juvenile $S$. horneri contributed $\sim 3-36 \%$ of its required $N$, potentially providing it with a competitive advantage. As DMAs remain poorly understood within macroalgal detrital systems, long term (15-28 days) laboratory decomposition time series were carried out to investigate the role of BNF throughout decomposition of the endemic macroalga, S. palmeri, and the invasive S. horneri. Nitrogenase activity increased drastically during the second phase of decomposition, when increasing microbial populations are typically thought to drive macroalgal degradation, with BNF rates associated with S. palmeri and S. horneri reaching up to 65 and $247 \mathrm{nmol} N \times g^{-1}(d w) \times \mathrm{h}^{-1}$, respectively. Stimulation of BNF rates by glucose and mannitol additions, up to $42 \times$ higher rates observed with $S$. palmeri, suggest that labile carbon may be limiting at varying degrees in these detrital systems. Comparable, if not higher, dark BNF rates relative to light incubations during $S$. horneri decomposition suggest an important contribution from heterotrophic $\mathrm{N}$ fixers. Inhibition of nitrogenase activity, up to $98 \%$, by sodium molybdate additions also suggest that sulfate reducers may be an important constituent of the detrital diazotrophic community. As labile $\mathrm{N}$ can become limiting to the microbial community during macroalgal decomposition, our results suggest that BNF may provide a source of new $\mathrm{N}$, alleviating this limitation. Additionally, while BNF is rarely considered as a source for $\mathrm{N}$ enrichment with aging macroalgal detritus, we found it to account for $\sim 1-$ $11 \%$ of $\mathrm{N}$ immobilized with decaying S. horneri. Our investigations suggest that DMAs may be globally important with Sargassum and potentially occur within other macroalgal detrital systems.

Keywords: heterotrophic nitrogen fixation, diazotrophic macroalgal associations (DMAs), Sargassum, decomposition, sulfate reducers 


\section{INTRODUCTION}

Benthic and pelagic marine macroalgae, encompassing three divisions (Rhodophyta, Chlorophyta, Phaeophyceae), are a diverse group of photoautotrophic organisms that extend across polar, temperate, and tropical latitudes (Keith et al., 2014). Species of brown macroalgae from the genus Sargassum truly highlight this cosmopolitan distribution as they occur in diverse benthic habitats along coastal zones throughout the world, spanning from the Gulf of California (Pacheco-Ruíz et al., 1998) to the rocky intertidal shores of the Japan Sea (Umezaki, 1984), occur in coral reefs such as the Great Barrier Reef (McCook, 1997) and form pelagic communities throughout the Sargasso Sea, Gulf of Mexico, and Gulf Stream (Butler and Stoner, 1984). Additionally, substrate-attached benthic macroalgae are often uprooted via different processes, e.g., exposure to waves and currents, storm events, or grazing, and transported offshore where they proliferate as rafts of drifting seaweed (Komatsu et al., 2008).

Benthic macroalgae can make important seasonal contributions to primary productivity in nearshore fringing reefs of the central Great Barrier Reef (Schaffelke and Klumpp, 1997) and dominate productivity along coastal ecosystems, contributing up to $50 \%$ of global coastal gross primary production (Duarte et al., 2005). Similarly, pelagic Sargassum communities can also make important contributions to upper ocean primary production with an input of $\sim 60 \%$ of total primary production in the upper $1 \mathrm{~m}$ of the water column in the Sargasso Sea (Coston-Clements et al., 1991). Although primary production by macroalgae provides fixed carbon to other organisms through leaching of dissolved organic carbon or direct grazing, the vast majority of macroalgal production (estimates up to 90\%; Mann, 1973) ultimately enters the detrital food chain or is sequestered in marine sediments or the deep ocean (Krause-Jensen and Duarte, 2016).

Macroalgae also create diverse habitats ranging from small drifting clumps of seaweed to structurally complex three dimensional communities such as giant kelp forests. These communities can host a rich assemblage of micro- and macro-organisms (e.g., prokaryotic and fungal epiphytes, a wide array of fishes, turtles and other vertebrates, gastropods, amphipods, nematodes, hydrozoans, and other invertebrates) that vary from larvae to juveniles to adults (Ingólfsson, 2000; Graham et al., 2007; Goecke et al., 2010; Abé et al., 2013). Furthermore, macroalgal habitats (e.g., Sargassum beds) can also control nutrient concentrations, $\mathrm{pH}$, dissolved oxygen $\left(\mathrm{O}_{2}\right)$ concentrations, and photon flux in the immediate ecosystem surrounding it (Komatsu, 1989; Lapointe, 1997; Zhang et al., 2008). The myriad of ecological functions that benthic, pelagic, or drifting macroalgae serve exemplifies their versatility and importance in marine ecosystems.

The success of benthic and pelagic macroalgae, such as the globally relevant Sargassum species, are largely dependent on the availability of light and nutrients. With regard to nutrients, nitrogen $(\mathrm{N})$ is usually reported as a major controlling factor in the growth cycle of macroalgae and oftentimes, it is the dominant limiting factor for macroalgal productivity (Gagné et al., 1982;
Hanisak, 1983; Fujita et al., 1989; Pedersen and Borum, 1996; Larned, 1998; Zhang et al., 2008). Macroalgae obtain N, along with other nutrients, from the water column where $\mathrm{N}$ can accumulate via different avenues including seasonal and local upwelling events (Gagné et al., 1982; Fujita et al., 1989), winter mixing events (Chapman and Craigie, 1977), nutrient excretions by associated organisms (Lapointe et al., 2014), nutrients from the underlying sediments, and eutrophication from $\mathrm{N}$ loading events such as wastewater discharge (Valiela et al., 1997).

Biological $\mathrm{N}$ fixation (BNF) is the conversion of dinitrogen gas $\left(\mathrm{N}_{2}\right)$ into a biologically available form of $\mathrm{N}$ (e.g., $\mathrm{NH}_{3}$ ) mediated by a specialized group of prokaryotic organisms known as diazotrophs. Diazotrophs use the nitrogenase metalloenzyme to tap into the vast dissolved reservoir of $\mathrm{N}_{2}$ and provide a new source of $\mathrm{N}$, making significant contributions to the global $\mathrm{N}$ budget and primary production (Capone, 2001). BNF associated with pelagic Sargassum species (i.e., S. fluitans, S. natans) has been examined by a number of investigators (e.g., Carpenter, 1972; Hanson, 1977; Phlips et al., 1986) with varying estimates of contributions of fixed $\mathrm{N}$ to sustain macroalgal productivity. In contrast, studies on benthic Sargassum species are less frequent (Phlips et al., 1986; Odintsov, 1992). Despite several additional accounts [as determined via the acetylene reduction (AR) method or stable isotope approach] of diazotrophic macroalgal associations (DMAs) observed with other benthic macroalgae (1) Codium decorticatum (Rosenberg and Paerl, 1981), (2) C. fragile (Head and Carpenter, 1975; Gerard et al., 1990), (3) Microdictyon sp., Dictyota sp. (Capone et al., 1977), (4) Acanthophora sp. (Goldner, 1980; France et al., 1998), (5) Laurencia sp. (Capone, 1977), and (6) Caulerpa sp. and Lobophora sp. (Tilstra et al., 2017), BNF is still rarely considered as a potential source of $\mathrm{N}$ for macroalgal productivity.

While there are a limited number of studies investigating BNF associated with living macroalgae, it remains virtually unexplored with decomposing macroalgal systems. In contrast, BNF dynamics have been routinely investigated with other macrophyte litter such as mangrove leaf detritus and senescing sea grass meadows which have repeatedly been shown to support diazotrophic activity (Gotto and Taylor, 1976; Zuberer and Silver, 1978; Capone and Budin, 1982; O’Donohue et al., 1991). The only prior publication (to our knowledge) that directly investigated BNF activity associated with decomposing seaweed reported higher BNF rates associated with Macrocystis pyrifera detritus compared to healthy M. pyrifera blades (Hamersley et al., 2015). Hamersley et al. (2015) proposed that while BNF did not contribute significantly to the $\mathrm{N}$ quota required during macroalgal production, it played an important role with $M$. pyrifera post-senescence by potentially improving the nutritional quality of the degrading macroalgal substrate as it entered the detrital food web.

Although Sargassum beds in native ecosystems serve important ecological functions and environmental services, the roles of various introduced Sargassum species (e.g., S. muticum, $S$. horneri) within non-native macroalgal systems suggest a potentially harmful ecological impact (Stæhr et al., 2000; Cruz-Trejo et al., 2015; Caselle et al., 2018). The introduction of an invasive macroalga, S. horneri, to the eastern Pacific 
(Miller et al., 2007) and its increasing range expansion throughout the Southern California ecosystem (Cruz-Trejo et al., 2015; Marks et al., 2015; Kaplanis et al., 2016) provided us with a unique opportunity to tackle many of the aforementioned gaps in the literature regarding DMAs. Primarily, we sought to investigate the role of diazotrophs throughout the life cycle of S. horneri to assess whether BNF provided an advantage to this globally important macroalga in a non-native ecosystem, thereby also expanding upon the limited literature regarding BNF associated with benthic Sargassum species in general. As BNF dynamics associated with decomposing macroalgal systems remain poorly understood, we also thought it pertinent to (1) investigate BNF associated with aging $S$. horneri detritus in comparison to other endemic species in the Southern California coastal ecosystem (e.g., S. palmeri) and (2) explore if diazotrophs may influence the nutritional quality of $S$. horneri detritus.

\section{MATERIALS AND METHODS}

\section{Sample Collection and Experimental Set Up}

Substrate attached S. horneri at various life stages, i.e., juvenile, immature, mature, and senescent, were collected throughout different seasons over 2 years (2016 and 2017) at various locations surrounding Santa Catalina Island, CA, United States (Supplementary Table S1). Substrate attached S. palmeri that was beginning to senesce was also collected during the summer of 2016 (Supplementary Table S1). Upon collection, most samples were transported back to the Wrigley Marine Science Center where the bulk of the experiments and incubations took place. However, there were some instances when fresh samples were transported back to the University of Southern California (USC) main campus in a bucket of seawater that was aerated with a bubbling stone prior to experimental setup.

For long term laboratory decomposition experiments, freshly collected samples were randomly separated into multiple $200 \mu \mathrm{m}$ white mesh litter bags and allowed to degrade inside continuous flow-thru seawater tanks. The 2016 experiments took place in outdoor tanks with shade screening resulting in $\sim 40-60 \%$ of ambient surface photosynthetically active radiation (PAR), resembling conditions experienced by floating rafts of $S$. horneri. The 2017 experiments took place in indoor tanks without any screening resulting in $\sim 4-10 \%$ of ambient surface PAR, resembling decomposition conditions more likely to exist in the benthos. A different litter bag was sub-sampled every few days and the macroalgal contents were apportioned into homogenous groups that were then incubated for $\sim 24-48 \mathrm{~h}$ in serum vials with different amendments for quantification of BNF rates via the AR method (discussed below). In order to track loss of biomass, the same litter bag was manually squeezed to remove excess water and the wet weight was recorded every few days over a 20-day period. The initial weight is considered to be at full saturation and every weight measured thereafter is reported as the percentage of biomass remaining relative to the initial weight (Supplementary Figure S1).
In the 2016 decomposition experiment, S. horneri and S. palmeri were sub-sampled for AR assays on days $0,5,11$, 21, and 28. All serum vials used for AR assays were incubated in the same outdoor tanks where macroalgal litter bags were undergoing long term decomposition. In the 2017 decomposition experiment, $S$. horneri was sub-sampled on days $0,3,8,12$, and 15 for AR assays. These serum vials were incubated inside a temperature and light controlled incubator held at a constant $18^{\circ} \mathrm{C}$ with 12 -h diel cycles at $\sim 3-10 \%$ of ambient surface PAR. From seasonal field sampling efforts, fresh macroalgal samples were placed immediately ( $\sim 2-5$ h upon collection) in serum vials and assayed for nitrogenase activity to quantify ambient BNF rates. Similar to the decomposition experiment, these serum vials underwent short-term incubations for $\sim 24-48 \mathrm{~h}$ either in the flow-thru seawater tank inside the laboratory $(\sim 4-10 \%$ PAR) or in a $16^{\circ} \mathrm{C}$ temperature controlled incubator with 12 -h diel cycles at $\sim 5 \%$ PAR.

\section{Light vs. Dark Assays}

Parallel light and dark assays took place for all fresh and longterm decomposition experiments. All light assays were set up by placing macroalgal samples in clear 14 or $27 \mathrm{~mL}$ serum vials with $0.2 \mu \mathrm{m}$ filtered seawater without any further changes to the illuminance. Dark assays took place in 14 or $27 \mathrm{~mL}$ serum vials wrapped in aluminum foil with $0.2 \mu \mathrm{m}$ filtered seawater. For the 2016 decomposition experiment of S. horneri and S. palmeri, dark vials were also purged with $\mathrm{N}_{2}$ gas for $\sim 1.5$ min before beginning the AR assays. Dark vials for the 2017 S. horneri decomposition experiment were not purged with $\mathrm{N}_{2}$ gas and light inhibition remained to be the only perturbation to these assays.

\section{Carbon Additions: Glucose and Mannitol Amendments}

Primary stocks of D-glucose $\left(\mathrm{C}_{6} \mathrm{H}_{12} \mathrm{O}_{6}\right)$ and mannitol $\left(\mathrm{C}_{6} \mathrm{H}_{14} \mathrm{O}_{6}\right)$ were made in the same batch of $0.2 \mu \mathrm{m}$ filtered seawater as what was used for incubating macroalgae in the serum vials for the AR assays. For the 2016 S. horneri and S. palmeri decomposition experiments, glucose and mannitol amendments at different concentrations were carried out in in both light and dark vials in parallel to the control light and dark assays. On day 0, $100 \mu \mathrm{M}$ of glucose and mannitol was added to all assays. However, glucose and mannitol amendments were increased to $1 \mathrm{mM}$ additions for all subsequent assays (i.e., days 5, 11, 21) throughout the decomposition experiment except on day 28 when only control assays were carried out due to a shortage in remaining biomass to carry out the carbon amendments.

\section{Sodium Molybdate Assays}

Primary stocks of sodium molybdate dihydrate $\left(\mathrm{Na}_{2} \mathrm{MoO}_{4} \cdot 2 \mathrm{H}_{2} \mathrm{O}\right)$, a known inhibitor of sulfate reducing bacteria (Oremland and Capone, 1988), were made in the same batch of $0.2 \mu \mathrm{m}$ filtered seawater as what was used for incubating macroalgae in the serum vials. For the duration of the 2017 S. horneri decomposition experiment (i.e., days $0,3,8,12$, and 15), $20 \mathrm{mM}$ sodium molybdate amendments were carried out 
in both light and dark vials concurrent to control light and dark assays.

\section{AR Assay}

The widely used AR assay was utilized to quantify ethylene $\left(\mathrm{C}_{2} \mathrm{H}_{4}\right)$ production and assess nitrogenase activity (Capone, 1993). For each amendment (e.g., control light/dark, glucose light/dark, etc.), triplicate 14 or $27 \mathrm{~mL}$ serum vials were capped with gray butyl stoppers and crimped with aluminum crimp caps before injecting with 1 or $2 \mathrm{~mL}$ of acetylene $\left(\mathrm{C}_{2} \mathrm{H}_{2}\right)$ gas (produced by reacting water with calcium carbide) using a disposable $\mathrm{BD}$ syringe with luer lock tips. Regardless of the size of the serum vial (14 vs. $27 \mathrm{~mL}$ ), the ratio of aqueous to gas phase was kept constant at $\sim 67: 33 \%$, respectively, and the volume of $\mathrm{C}_{2} \mathrm{H}_{2}$ injected ( $\sim 20 \%$ of the gas phase or $\sim 7 \%$ of total volume) was enough to saturate the nitrogenase enzyme (Flett et al., 1976). The vials were gently shaken ( $\sim 5$ inversions) upon injection of $\mathrm{C}_{2} \mathrm{H}_{2}$ to equilibrate the vapor phase with the aqueous phase and incubated for $\sim 24-48 \mathrm{~h}$ in the aforementioned temperature and light conditions. Negative controls without any $\mathrm{C}_{2} \mathrm{H}_{2}$ introduced into the serum vials containing macroalgae were also routinely tested in order to ensure there was no background $\mathrm{C}_{2} \mathrm{H}_{4}$ production during these incubations.

Starting with a $\mathrm{T}_{0}$ time-point upon initial $\mathrm{C}_{2} \mathrm{H}_{2}$ injection, $100 \mu \mathrm{L}$ subsamples were taken from the headspace of all replicates using a Hamilton gas tight syringe and injected into a gas chromatograph (Shimadzu Mini 2) equipped with a flame ionization detector at different time-points (every $\sim 3-8 \mathrm{~h}$ ) throughout the duration of the incubation. The PeakSimple chromatography data system was used to quantify $\mathrm{C}_{2} \mathrm{H}_{4}$ peak heights at these different time-points and subsequently converted to nmol of $\mathrm{C}_{2} \mathrm{H}_{4}$ produced (Capone, 1993; Breitbarth et al., 2004). Instantaneous rates between time-points which contributed less than $30 \%$ to the overall rate were used to identify occurrences of severe lags in the beginning of incubations and plateaus toward the end of an incubation. Finally, rates of $\mathrm{C}_{2} \mathrm{H}_{4}$ production excluding lags and plateaus were determined using linear regressions and subsequently, theoretical BNF rates were calculated using a 3:1 $\mathrm{C}_{2} \mathrm{H}_{2}$ reduced: $\mathrm{N}_{2}$ reduced ratio (Capone, 1993) and multiplied by 2 to express as $\mathrm{nmol} \mathrm{N} \times \mathrm{g}^{-1}$ (dry weight, $\mathrm{dw}) \times \mathrm{h}^{-1}$.

\section{$\mathrm{C}$ and $\mathrm{N}$ Content and $\delta^{15} \mathrm{~N}$ Analysis}

Throughout the 2017 S. horneri decomposition experiment, fresh detritus (FD) was subsampled on days $0,3,8,12$, and 15 for $\mathrm{CN}$ and $\delta^{15} \mathrm{~N}$ isotope analysis. Additionally, a portion of the FD subsampled on the aforementioned days were incubated for $\sim 48 \mathrm{~h}$ for AR assays and retrieved on days 2, 5, 10, 14, and 17 for $\mathrm{CN}$ analysis. These post-incubation detritus samples will be referred to as PID. Dried macroalgal samples, stored in aluminum pockets were transported back to the USC main campus where they were homogenized to a fine powder using a mortar and pestle. All samples ranging between $\sim 1$ and $1.3 \mathrm{mg}$ were then encapsulated in tin capsules and pelletized for elemental $(\mathrm{CN})$ and/or isotopic $\left({ }^{15} \mathrm{~N}\right)$ analysis on a Micromass IsoPrime continuous flow isotope ratio mass spectrometer with $\mathrm{CHN}$ analyzer/sample front ends.

\section{Light and $\mathrm{O}_{2}$ Measurements}

PAR for the surface ocean $(<1 \mathrm{ft}$.), outdoor tank, indoor tank, and incubator was measured at the same time (within $10 \mathrm{~min}$ ) using a handheld quantum PAR meter (Biospherical Instruments Inc., San Diego, CA, United States) over multiple days. The surface ocean readings were assumed to be fully saturated and all other conditions are expressed as a percentage relative to the ambient surface conditions from that day. Dissolved $\mathrm{O}_{2}$ concentrations inside an open $27 \mathrm{~mL}$ serum vial with $0.2 \mu \mathrm{m}$ filtered seawater and senescent $S$. horneri or without any $S$. horneri were measured using an $\mathrm{O}_{2}$ microelectrode $(\mathrm{Ox}-50$, Unisense A/S, Aarhus, Denmark). Multiple depth profiles, over $\sim 30 \mathrm{~mm}$, were taken at $1 \mathrm{~mm}$ intervals and several depth profiles at close proximity to the seaweed were also taken at the $\mu \mathrm{m}$ scale using the micromanipulator (Unisense A/S).

\section{Statistical Analysis}

Since not all assumptions (i.e., normality, homoscedasticity) were met for standard tests such as ANOVA, non-parametric equivalents of the one-way ANOVA (Wilcox, 2012b) and twoway ANOVA (Wilcox, 2012c) were utilized to analyze the data sets for BNF rates, $\% \mathrm{C}, \% \mathrm{~N}$, and $\mathrm{C}: \mathrm{N}$ ratios. In conjunction with these analyses, a non-parametric equivalent to the classic Tukey's HSD post hoc analysis which allows heteroscedasticity, lincon function on the R software (Wilcox, 2012a), was utilized to conduct pairwise comparisons between various treatments for the different data sets. Statistically significant differences for $p$-values less than $0.05,0.01$, and 0.001 are included in the various figures.

\section{RESULTS}

\section{Role of BNF During Different Life Stages of S. horneri}

Seasonal BNF rates associated with freshly collected $S$. horneri (Supplementary Table S2) yielded significantly lower rates than those associated with decomposing macroalgal detritus (Supplementary Tables S3, S4). BNF rates were not detectable with juvenile and immature $S$. horneri collected during the fall and winter. However, BNF rates close to the limit of detection $\left[\sim 0.7-2 \mathrm{nmol} \mathrm{N} \times \mathrm{g}^{-1}(\mathrm{dw}) \times \mathrm{h}^{-1}\right]$ were observed with adult $S$. horneri toward the end of winter. Higher BNF rates $\left[\sim 12-24 \mathrm{nmol} \mathrm{N} \times \mathrm{g}^{-1}(\mathrm{dw}) \times \mathrm{h}^{-1}\right]$ associated with freshly collected $S$. horneri were measured in the summer when necrosis was already beginning to take place with the seaweed upon time of collection. The highest BNF rates [ 28-91 nmol $\mathrm{N} \times \mathrm{g}^{-1}(\mathrm{dw}) \times \mathrm{h}^{-1}$ ] with living $S$. horneri was associated with juveniles in the late summer (Figure 1).

Relative growth rates expressed in terms of percent increases in blade weight or fresh weight per day, ranging from 4 to $5.2 \%$ (Gao and Hua, 1997; Choi et al., 2008), were used to estimate increases in biomass of whole juveniles collected in this study as $\mathrm{g}(\mathrm{dw})$ per day. These growth rates were found to be in the same range as growth rates of different $S$. horneri juveniles reported in other studies (Umezaki, 1984; Yoshida et al., 2001), ranging 


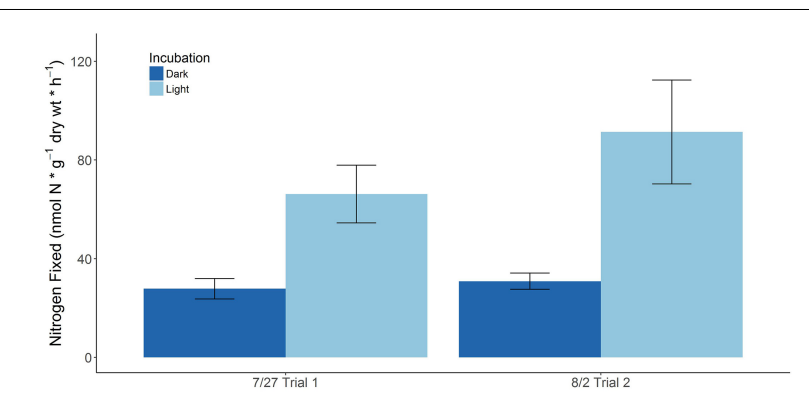

FIGURE 1 | BNF rates associated with juvenile $S$. horneri recruits on two separate trials (error bars represent SE).

from 0.003 to $0.01 \mathrm{~g}$ (dw) per day (Supplementary Table S5). In concert with the estimated and previously reported growth rates of $S$. horneri juveniles from approximately the same time, the average $\% \mathrm{~N}(\sim 1.01 \pm 0.04 \%, 1.07 \pm 0.07 \%)$ of $S$. horneri juveniles collected in July and August, respectively, were used to calculate $\mathrm{g}$ of $\mathrm{N}$ required to sustain growth of $S$. horneri juveniles. As both trials in July and August yielded higher BNF rates in the light than the dark, the average dark and light BNF rate $[\sim 47$ and $61 \mathrm{nmol}$ $\mathrm{N} \times \mathrm{g}^{-1}(\mathrm{dw}) \times \mathrm{h}^{-1}$, respectively] was assumed to represent the overall diazotrophic activity in a full day. This was used to calculate potential contributions of fixed $\mathrm{N}$ from diazotrophic activity to meet $\mathrm{N}$ demands for $S$. horneri juveniles during this period. The contribution of fixed $\mathrm{N}$ from diazotrophic activity ranged from 3 to $36 \%$ with a mean contribution of $\sim 9.6 \%$. The results from this analysis can be found in the Supplementary Table S6.

\section{Trends in Diazotrophic Activity Throughout Macroalgal Decay}

Two separate laboratory decomposition experiments carried out in subsequent summers showed recurring shifts in diazotrophic activity associated with the degradation of the invasive macroalga, S. horneri (Figures 2A,B). Initially, when seaweed samples were relatively fresh and only beginning to senesce, lower BNF rates were observed $\left[\sim 12-24 \mathrm{nmol} \mathrm{N} \times \mathrm{g}^{-1}(\mathrm{dw}) \times \mathrm{h}^{-1}\right]$. Following just a few days ( $\sim 3-5$ days) of decomposition during which there was $\sim 20 \%$ loss in biomass (Supplementary Figure S1), there was a distinct increase (up to $10 \times$ ) in diazotrophic activity with $\mathrm{BNF}$ rates reaching up to $247 \mathrm{nmol} \mathrm{N} \times \mathrm{g}^{-1}(\mathrm{dw}) \times \mathrm{h}^{-1}$ (Figures 2A,B). This increase in nitrogenase activity was sustained for a number of days (until day $\sim 11-12$ ) by which time there was an additional $\sim 40 \%$ loss in biomass (Supplementary Figure S1). This trend in rapid biomass loss continued from day 12 to 14 during which time there was a further $~ 9 \%$ loss in biomass (Supplementary Figure S1). The ensuing plateau in macroalgal degradation from days 14 to 20, with only $\sim 1 \%$ loss in biomass, coincided with a substantial decrease in diazotrophic activity ( $\sim$ day 15$)$, resulting in $B N F$ rates comparable to the initial rates or in some cases, lower than the initial rates (Figures 2A,B and Supplementary Figure S1). These same trends in diazotrophic activity were also observed during decomposition of the endemic Sargassum species, S. palmeri
(Figure 2C). Lastly, while several instances of S. horneri dark assays yielded higher BNF rates, dark assays of $S$. palmeri did not result in higher nitrogenase activity than light assays (Figure 1). All calculated BNF rates for control treatments are reported in the Supplementary Tables S3, S4.

\section{Impact of Carbon Additions on BNF Rates}

For S. horneri, we observed that additions of $100 \mu \mathrm{M}$ glucose and mannitol on day 0 stimulated nitrogenase activity in the dark assays by a factor of $\sim 3$ and 2.5 , respectively, but no stimulation of $\mathrm{BNF}$ rates were observed in the light assays (Figures 3A,B). In contrast, there were low to non-detectable BNF rates associated with $S$. palmeri with the same carbon amendments (Figures 3C,D). Higher concentrations of glucose (ranging from $\sim 56 \mu \mathrm{M}$ to $56 \mathrm{mM}$ ) have been used in prior investigations looking at DMAs (Head and Carpenter, 1975) and thus, in order to ensure an increase in measurable nitrogenase activity, the amendment concentration for both glucose and mannitol were increased to $1 \mathrm{mM}$ for all subsequent days which yielded mixed results.

In both light and dark assays for S. horneri, adding $10 \times$ more glucose and mannitol failed to further stimulate the diazotrophic community associated with it until day 21. On day 21, glucose and mannitol amendments in the dark and light assays stimulated $\mathrm{BNF}$ rates by $5.3-15$, but even these elevated rates were either comparable to or lower than the control rates observed earlier in the decomposition period (Figure 3A). For S. palmeri, higher concentrations of glucose and mannitol stimulated BNF rates ( $\sim 3.7$ - and 3 -fold, respectively) on day 5 in dark assays but failed to further stimulate nitrogenase activity in the light assays (Figures 3C,D). However, for the remainder of the decomposition period of $S$. palmeri, carbon amendments greatly stimulated BNF rates (with up to $\sim 42$-fold stimulation) in both light and dark assays (Figures 3C,D). A complete list of BNF rates for various amendments with both species of macroalgae are available in the Supplementary Table S3.

\section{Impact of Sodium Molybdate Amendments on Nitrogenase Activity}

It is evident in the dark assays that the addition of $20 \mathrm{mM}$ sodium molybdate routinely suppressed nitrogenase activity throughout most of the decomposition period and with increasing intensity, reaching the highest reduction ( $\sim 98 \%)$ in BNF rates on day 12 (Figure 4A). The same amendments produced mixed results in the light assays but apart from day 0 where there was stimulation of nitrogenase activity, it either severely inhibited (maximum reduction of $\sim 95 \%$ on day 12 ) or did not significantly impact nitrogenase activity (Figure 4B). The complete list of BNF rates are available in the Supplementary Table S4.

\section{Changes in $\mathrm{C}$ and $\mathrm{N}$ Content (\%), C:N Ratio and $\delta^{15} \mathrm{~N}$ Signature of Aging S. horneri Detritus}

There is an overall decrease in C, by $2.73 \%$, with fresh S. horneri detritus subsampled over the first 12 days of 


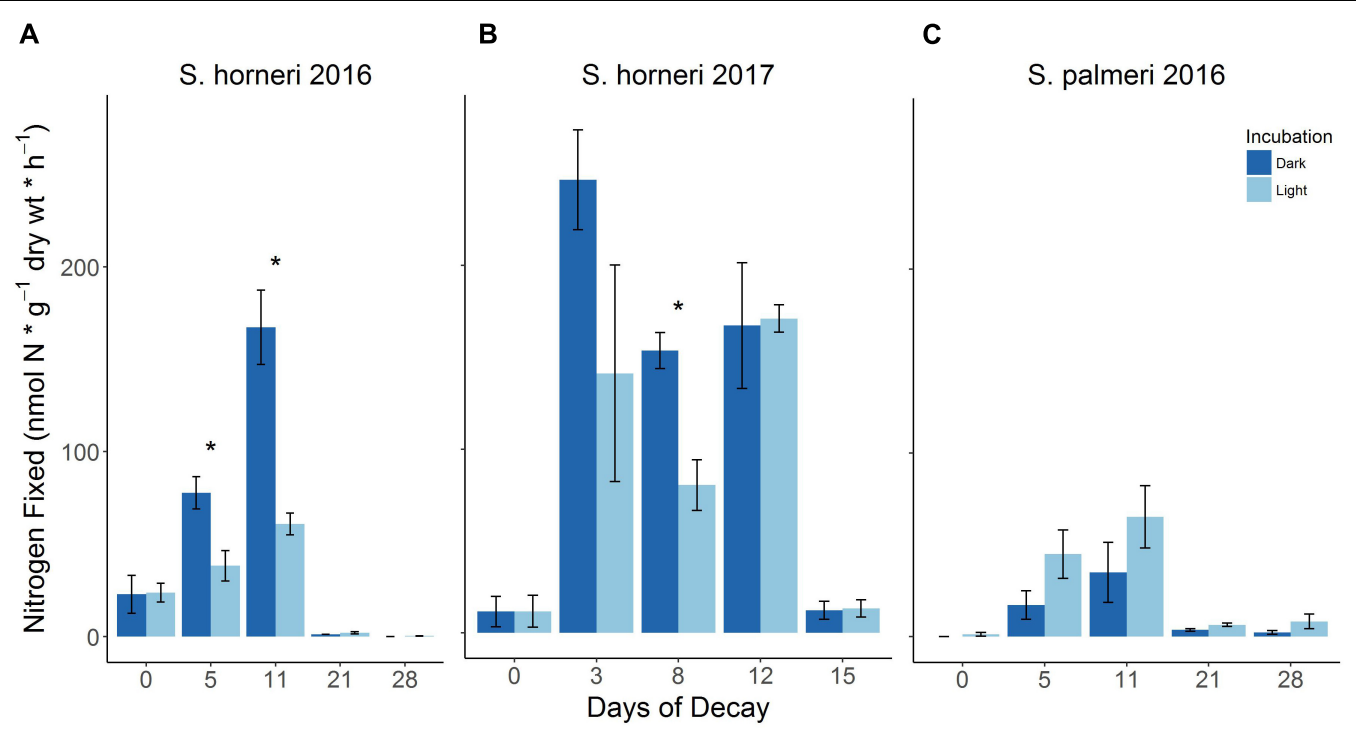

FIGURE 2 | BNF rates associated with decomposing S. horneri (A,B) and S. palmeri (C) under dark and light incubations during two summers (2016 and 2017) (error bars represent SE). * $p<0.05$.

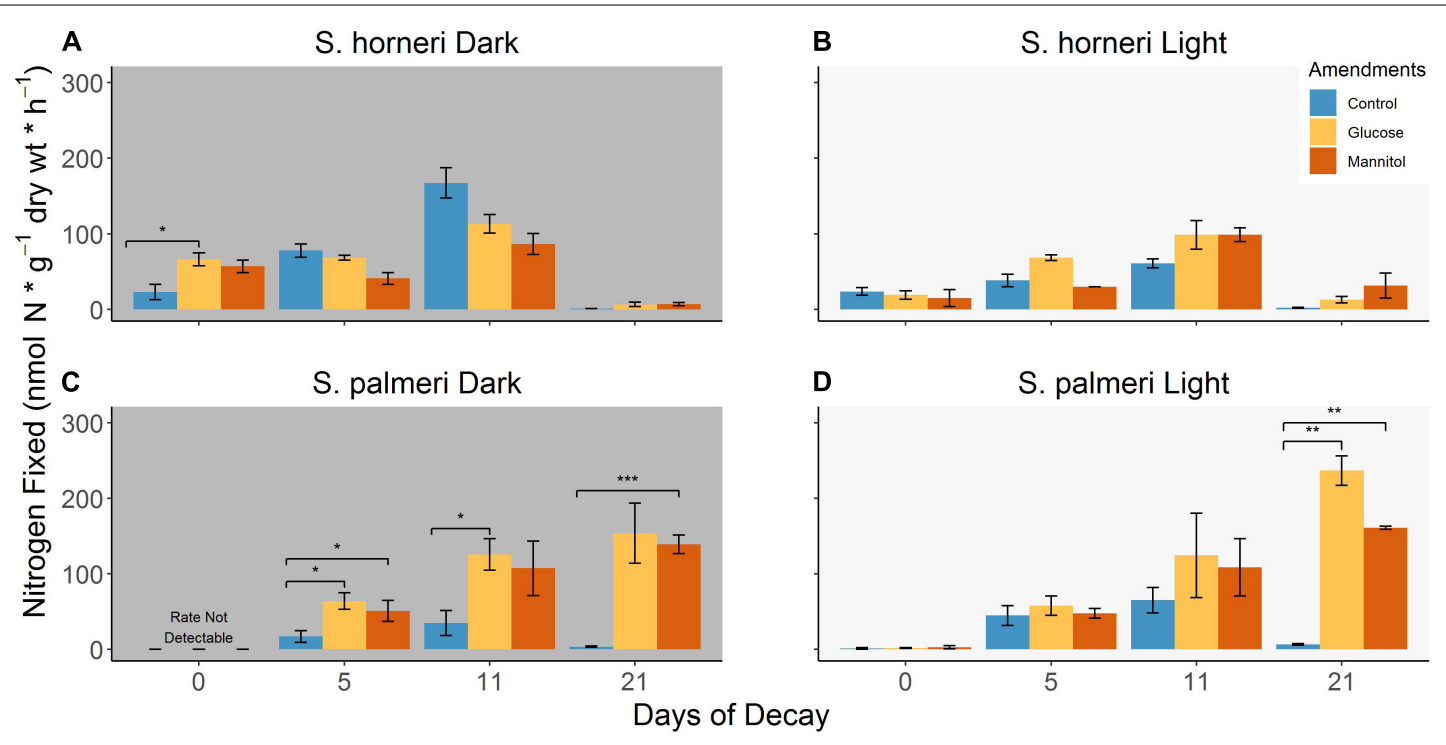

FIGURE 3 | (A-D) Differences in BNF rates associated with decomposing S. horneri and S. palmeri between control conditions, glucose (100 $\mu$ M/1 mM) and mannitol $(100 \mu \mathrm{M} / 1 \mathrm{mM})$ additions under dark and light incubations (error bars represent SE). ${ }^{*} p<0.05,{ }^{* *} p<0.01,{ }^{* * *} p<0.001$.

decomposition (Figure 5A). In contrast, $\mathrm{N}$ increases by $40.8 \%$ with FD during this time (Figure 5B). Between day 12 and 15 , FD exhibited a sudden increase in C by $20 \%$ and $\mathrm{N}$ continued to increase by $14 \%$ (Figures $\mathbf{5 A}, \mathbf{B}$ ). The resulting C:N ratio with FD decreased by $31 \%$ over the first 12 days of decomposition and despite increasing from day 12 to 15 by $5.2 \%$, the final $\mathrm{C}: \mathrm{N}$ ratio exhibited an overall decrease of $27.3 \%$ (Figure 5C). The $\delta^{15} \mathrm{~N}$ of FD continuously decreased from $12.2 \%$ to $9.3 \%$ over the course of the decomposition, resulting in an overall decrease of $24.1 \%$ by day 15 (Figure 5D).
There is also an overall decrease in C, between 6.1 and $16.4 \%$, with PID recovered at the end of $\sim 48$-h dark and light incubations under control and sodium molybdate treatments over the first 12 days of decomposition (Figure 5A). Similar to the increase observed with day $15 \mathrm{FD}$, PID recovered at the end of this incubation also exhibited an increase in C, between 3.5 and $10 \%$, amongst all treatments (Figure 5A). All PID exhibited increases in N, between 52.2 and $74.7 \%$, over the first 8 days of decomposition (Figure 5B). Subsequently, there was an overall decrease in N, between 8.4 and $29.4 \%$, with all PID over the remainder of the decomposition experiment (Figure 5B). Despite 
A

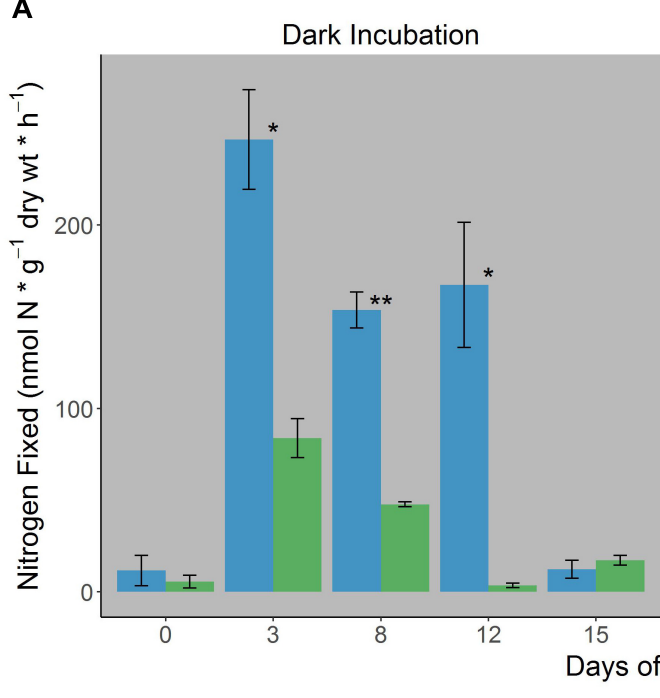

B

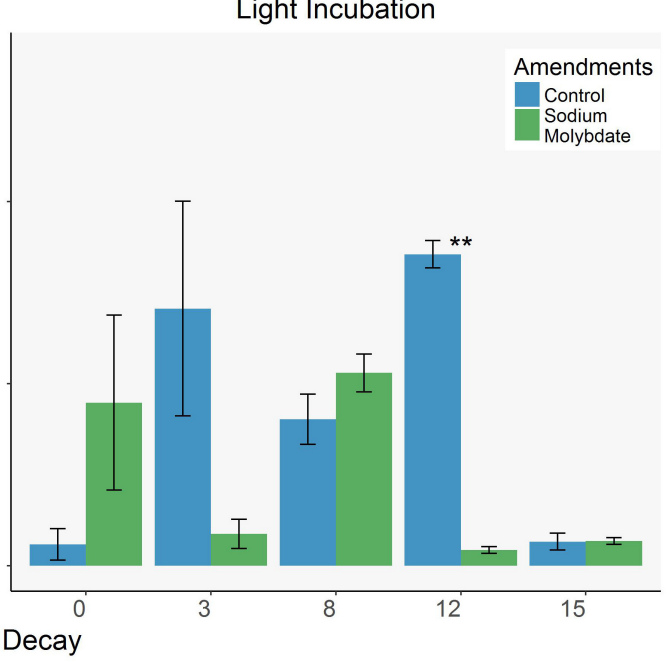

FIGURE 4 | (A,B) Differences in BNF rates associated with decomposing S. horneri between control conditions and sodium molybdate (20 mM) additions under dark (left) and light (right) incubations (error bars represent SE). ${ }^{*} p<0.05,{ }^{* *} p<0.01$.

A

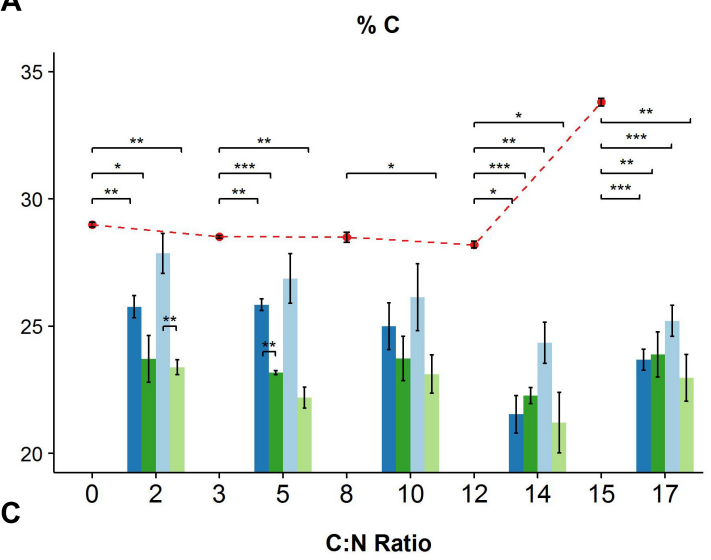

B

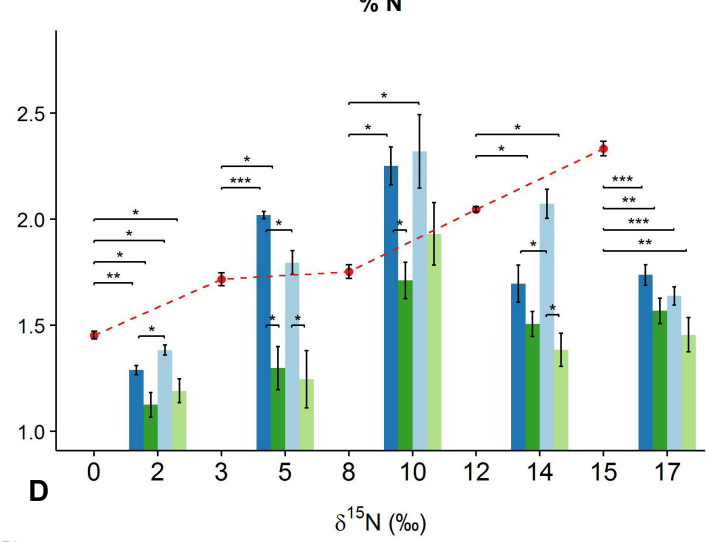

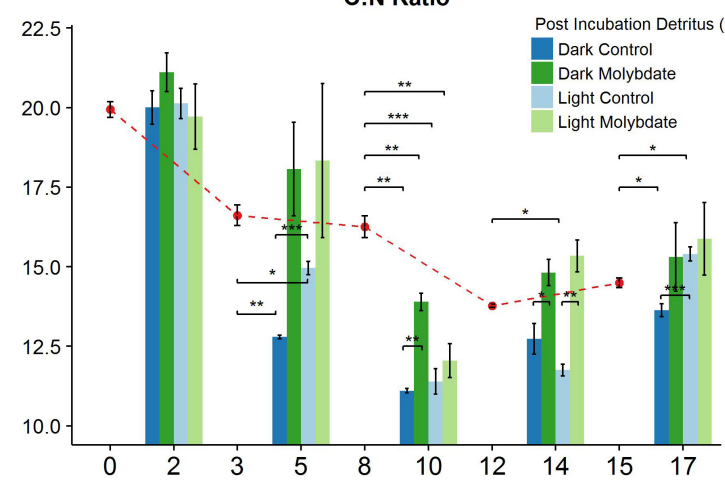

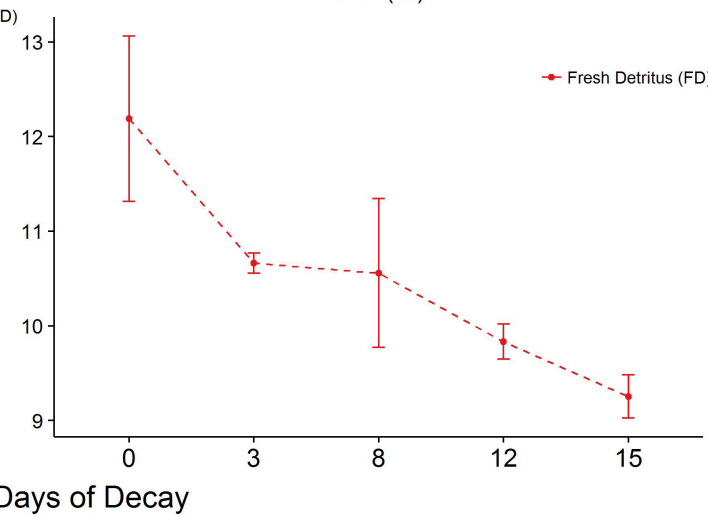

FIGURE 5 | Changes in \%C (A), \%N (B) and C:N ratio (C) associated with decomposing S. horneri in control (blue) and molybdate amendments (green) in both dark and light incubations as well as pre-incubation samples (red dashed line) (2017). Additional changes in $\delta^{15} \mathrm{~N}$ (D) with fresh detritus throughout decomposition (error bars represent SE). ${ }^{*} p<0.05,{ }^{* *} p<0.01,{ }^{* * *} p<0.001$. 
this decrease at the end, all PID were still relatively enriched, by 18.5 to $39.4 \%$, in $\mathrm{N}$ compared to PID from the onset of decomposition (Figure 5B). The resulting C:N ratio for all PID exhibit an inverse pattern to the $\% \mathrm{~N}$ trends, expressing an overall decline over the first 8 days of decomposition followed by an increase until the end of the decomposition experiment (Figure 5C). Despite this increase at the end, there is an overall decrease with the C:N ratio of PID at the end of decomposition relative to the initial (day 2) PID (Figure 5C). The PID recovered from sodium molybdate treatments resulted in higher $\mathrm{C}: \mathrm{N}$ ratio compared to the control treatments throughout the duration of the experiment (Figure 5C).

Control and sodium molybdate incubations for $\sim 48 \mathrm{~h}$ in the dark and light repeatedly resulted in PID that was more depleted, between 3.9 and $32.1 \%$, in C relative to the FD (Figure 5A). For the most part, sodium molybdate incubations in the dark and light also resulted in PID that were more depleted, between 5.1 and $17.4 \%$, in C compared to control PID from parallel incubations (Figure 5A). While control PID in the light repeatedly resulted in higher $\% \mathrm{C}$ than the dark incubations, the opposite trend was observed with sodium molybdate treatments which consistently resulted in slightly higher $\% \mathrm{C}$ with substrate recovered from dark incubations (Figure 5A).

Control incubations in the dark and light resulted in PID that were depleted, between 4.8 and $29.7 \%$, in $\mathrm{N}$ compared to FD at the beginning (day 0) and end (day 15) of decomposition (Figure 5B). However, PID retrieved at the end of day 3 and day 8 from dark and light control incubations exhibited higher $\mathrm{N}$, between 4.6 and $32.4 \%$, relative to the FD collected on those corresponding days (Figure 5B). While PID recovered at the end of day 12 light incubations resulted in slightly higher $\mathrm{N}$, by $1.26 \%$, PID from dark incubations were $17.1 \%$ more depleted in $\mathrm{N}$ compared to the FD collected initially on day 12 (Figure 5B). Apart from day 8 when PID in the light were more enriched in N, by $10.1 \%$, PID recovered at the end of both light and dark sodium molybdate incubations were more depleted in $\mathrm{N}$, between 2.4 and $37.6 \%$, compared to corresponding FD subsampled on days 0,3 , 8, 12, and 15 (Figure 5B). For both dark and light incubations, PID from sodium molybdate treatments always resulted in lower $\mathrm{N}$, between 9.8 and $35.7 \%$, compared to control PID from parallel incubations (Figure 5B). The $\% \mathrm{C}, \% \mathrm{~N}, \mathrm{C}: \mathrm{N}$ ratio, and $\delta^{15} \mathrm{~N}$ values for the aforementioned samples can be found in the Supplementary Table S7.

From all treatments throughout the decomposition experiment, there were several instances, on days 3 and 8 , when PID exhibited higher mean $\% \mathrm{~N}$ relative to $\mathrm{FD}$ collected at the beginning of the incubation (Figure 5B). Assuming a dry weight of $1 \mathrm{~g}$ of $S$. horneri detritus, the theoretical mass of $\mathrm{N}(\mathrm{mg})$ required to result in the observed increase in $\% \mathrm{~N}$ at the end of the incubation was calculated. The average BNF rates associated with the corresponding treatments, expressed as nmol $\mathrm{N} \times \mathrm{g}^{-1}(\mathrm{dw}) \times \mathrm{h}^{-1}$, were transformed into nmol of $\mathrm{N}$ fixed by multiplying the BNF rates by the assumed dry weight of the $S$. horneri detritus (1 g) and length of the incubation $(\sim 48 \mathrm{~h})$ and subsequently converted to $\mathrm{mg}$ of $\mathrm{N}$. Lastly, the percent contribution of $\mathrm{BNF}$ to $\mathrm{N}$ immobilization was calculated by dividing the theoretical mass of $\mathrm{N}(\mathrm{mg})$ required by the theoretical mass of $\mathrm{N}$ (mg) fixed during the incubation. The percent contribution to $\mathrm{N}$ immobilization by $\mathrm{BNF}$ ranged from 0.94 to $10.6 \%$ with an average contribution of $4.5 \%$. The complete results can be found in the Supplementary Table S8.

\section{DISCUSSION}

\section{Role of BNF in N Acquisition by Living S. horneri}

Throughout much of the life cycle of S. horneri, nitrogenase activity was not detectable or exhibited relatively low BNF rates that yielded insignificant amounts of fixed $\mathrm{N}$ to support macroalgal productivity. However, on two separate occasions, active BNF was observed with living S. horneri juveniles (5$8 \mathrm{~cm}$ long) collected during late July and early August of 2017 (Figure 1). Ambient nutrient concentrations are usually at their minimum during late summer in the Southern California Bight and one study conducted at Santa Catalina Island (same site as this study) found the low nutrient concentrations in the surrounding waters during this time to be insufficient to support maximal growth of the endemic macroalgae, $M$. pyrifera (Zimmerman and Kremer, 1984). Similarly, it may also be possible that the low nutrient conditions are not ideal to support growth of S. horneri juveniles. Thus, appreciable amounts of fixed $\mathrm{N}, \sim 3-36 \%$ of required $\mathrm{N}$ with an average contribution of $\sim 9.6 \%$, derived from diazotrophic activity during this time might potentially supplement their $\mathrm{N}$ requirement and thereby provide a competitive edge. These values are comparable to previous estimates of BNF contributions to sustain macroalgal productivity of various species such as C. decorticatum ( 5\%; Rosenberg and Paerl, 1981), Laurencia sp. (14-18\%; Capone, 1977), and pelagic Sargassum community ( 40\%; Hanson, 1977). Subsequent sampling efforts of juveniles in mid-September, October and late-November resulted in undetectable rates of BNF. Substantial increases in nutrient concentrations during the fall and winter, with maximum nitrate concentrations observed during this time (Zimmerman and Kremer, 1984) may explain the absence of BNF activity associated with S. horneri and potential shift back to nutrient uptake from the surrounding water column to sustain its growth and productivity.

\section{Significance of BNF Activity Associated With Decomposing Sargassum Detritus}

It is well established that various marine macrophytes such as salt marsh grasses (Valiela et al., 1985), mangrove leaves (Cundell et al., 1979) and sea grasses (Godshalk and Wetzel, 1978) undergo an initial phase of rapid biomass loss due to autolysis and leaching of soluble compounds. This is followed by a longer phase of biomass loss driven by microbial degradation of organic matter before entering the slowest phase of decay due to the refractory nature of the remaining detritus. Similarly, numerous studies have also observed macroalgal decay to follow this three-phase decomposition model (Hunter, 1976; Robinson et al., 1982; Smith and Foreman, 1984; Williams, 1984; Rieper-Kirchner, 1989). Furthermore, the trend of biomass loss observed in this study 
(Supplementary Figure S1) also adheres to this three-phase decomposition model.

Observations of microbial densities throughout these three phases have generally found there to be relatively low microbial biomass during the initial phase of decomposition. This is followed by a rapid increase in microbial colonization, indicative of a transition to microbial degradation of macroalgal detritus, with maximal microbial biomass being sustained for several days before microbial populations decrease, marking the final shift toward a more recalcitrant macroalgal detritus (Robinson et al., 1982; Rice and Hanson, 1984; Rieper-Kirchner, 1989; Sathe-Pathak et al., 1993). Recurring shifts in nitrogenase activity during decomposition of $S$. horneri and S. palmeri resemble this characteristic shift in microbial biomass, though with a much steeper decrease in BNF rates toward the end of the decomposition period (Figure 2). If the diazotrophic population is assumed to be changing in a similar fashion to the whole microbial community, the lower BNF activity observed at the beginning and end of decomposition could be attributed to potentially lower diazotrophic biomass present during the initial and terminal phases of decomposition. The BNF hot spot observed in the middle of decomposition may be a result of greater diazotrophic recruitment concomitant with increasing microbial populations that generally transpires during the second phase of macroalgal decomposition.

As most macroalgae have a relatively high C:N ratio $(>20: 1$ as observed with $S$. horneri samples in this study), increased microbial colonization during macroalgal degradation and rapid utilization of resources would lead to depletion in $\mathrm{N}$ before C. This may result in $\mathrm{N}$ limitation of the organic rich macroalgal substrate, thereby creating a niche for $\mathrm{N}$ fixing organisms. Several studies have shown additions of $\mathrm{N}$ to support greater microbial populations associated with macroalgal detritus. Consequently, increased microbial biomass were observed to utilize more of the available detrital carbon, expediting macroalgal degradation and highlighting the potential for $\mathrm{N}$ limitation to retard microbial degradation and impact the overall rate of macroalgal decomposition (Tenore et al., 1979; Robinson et al., 1982; Rice and Hanson, 1984). Additionally, it is also well established that $\mathrm{N}$ enrichment observed with aging macroalgal detritus does not necessarily indicate an increasing pool of labile $\mathrm{N}$ (e.g., proteins, amino acids) but rather, it might be an accumulation of recalcitrant $\mathrm{N}$ which also results in N limitation (Rice, 1982). BNF may provide new, bioavailable $\mathrm{N}$ for the associated microbial community, possibly alleviating $\mathrm{N}$ limitation and stimulating microbial degradation of macroalgae.

Interestingly, BNF rates associated with freshly collected S. horneri, which has been noted to begin senescing in its nonnative eastern Pacific habitat during the spring (Miller et al., 2007; Cruz-Trejo et al., 2015), expressed a seasonal increase toward the beginning of summer when it was physically observed to be senescent. Similarly senescing S. horneri in the western Pacific (Yoshida et al., 1998, 2001) might also potentially support diazotrophic activity as they form drifting rafts during spring to early summer (Komatsu et al., 2007, 2008; Yatsuya, 2008; Mizuno et al., 2014). Additionally, despite having a relatively longer floating period due to its lower density (Yatsuya, 2008),
S. horneri debris have also been found on the offshore deep sea floor during the summer (Kokubu et al., 2012). Therefore, it may also be possible that sinking S. horneri debris may further serve as a niche for diazotrophs in the deep sea benthos.

\section{Presence of Heterotrophic N Fixers}

In different marine ecosystems such as the anoxic waters $(200 \mathrm{~m})$ of the Baltic Sea (Farnelid et al., 2013), aphotic zone $(500$ and $885 \mathrm{~m})$ in the San Pedro Basin (Hamersley et al., 2011), and a wide assortment of benthic systems (Howarth et al., 1988), dark incubations have been utilized to estimate rates of heterotrophic BNF. While dark BNF rates could also include contributions from chemoautotrophic and methanotrophic diazotrophs, we are assuming BNF in the absence of light to be primarily a result of heterotrophic BNF. In this study, dark vials were purged with $\mathrm{N}_{2}$ gas in the 2016 S. horneri and S. palmeri decomposition experiment to promote an anaerobic environment and to protect the nitrogenase enzyme from oxygen toxicity and ensure measurable rates of BNF. While it could be argued that purging dark vials with $\mathrm{N}_{2}$ gas and leaving the light vials unperturbed might have resulted in elevated dark BNF rates in the first experiment, the 2017 S. horneri decomposition experiment, which utilized unpurged dark and light vials, also consistently exhibited higher rates of BNF associated with aging $S$. horneri detritus in the dark than in the light (Figures 2A,B). The second experiment, despite using unpurged vials, also expressed higher overall dark BNF rates compared to the 2016 experiment. Furthermore, similarly prepared dark, anaerobic assays routinely yielded lower BNF rates throughout the decomposition of S. palmeri (Figure 2C). These findings suggest that laboratory perturbations of dark vials in the first $S$. horneri experiment most likely did not provide any significant advantage to specific physiological groups of $\mathrm{N}$ fixers in the dark (Figure 2).

$\mathrm{O}_{2}$ depth profiles in an uncapped, illuminated serum vial containing senescent $S$. horneri samples in $0.2 \mu \mathrm{m}$ filtered seawater showed that $\mathrm{O}_{2}$ concentrations drop well below hypoxic levels, $<63 \mu \mathrm{M}$ as defined for coastal ecosystems (Middelburg and Levin, 2009), when approaching the thicket of $S$. horneri but remain constant when only exposed to seawater (Supplementary Figures S2A,B). Furthermore, depth profiles measured using an $\mathrm{O}_{2}$ microelectrode reveal that $\mathrm{O}_{2}$ concentrations can drop close to $0 \mu \mathrm{M}$ when in close proximity to senescent $S$. horneri particles (Supplementary Figures S2C,D). As observed with colonies of Trichodesmium (Paerl et al., 1989), localized areas of $\mathrm{O}_{2}$ consumption probably lead to formation of microaerobic niches with aging macroalgal detritus and provide protection from oxygen toxicity to diazotrophs. Additionally, heterotrophic respiration and inhibition of overall photosynthetic activity in the dark assays could have also prevented accumulation of high concentrations of $\mathrm{O}_{2}$ in the vials and further alleviated the nitrogenase enzyme from oxygen toxicity, resulting in higher rates of BNF in dark assays throughout the decomposition of S. horneri. As the exact nature of the diazotrophic population is currently unknown, $\mathrm{N}$ fixers in these detrital systems are most likely employing an array of 
methods to protect the nitrogenase enzyme from oxygen toxicity (Fay, 1992).

Similar to S. palmeri, dark BNF rates associated with living $S$. horneri juveniles were also consistently lower than in the light, suggesting a lesser contribution from heterotrophic $\mathrm{N}$ fixers in these systems (Figures 1, 2C). One possible explanation for higher dark BNF rates observed with decomposing $S$. horneri detritus compared to aging S. palmeri detritus might be differences in the diversity, abundance, and activity of the heterotrophic diazotrophs associated with the different macroalgae. Similarly, the difference in dark BNF rates associated with $S$. horneri at different life stages, i.e., juvenile vs. decomposing, leads us to hypothesize that there are most likely changes in the diazotrophic community composition associated with the host macroalga throughout its life cycle. This has been suggested with changes in the general microbial community associated with different macroalgae (Goecke et al., 2010) and future molecular work specifically targeting the nifH gene would better elucidate this hypothesis.

In many marine systems such as the oligotrophic open ocean and with previously reported DMAs (e.g., pelagic Sargassum species), phototrophic diazotrophs (e.g., Trichodesmium, Crocosphaera, Calothrix, Dichothrix fucicola) are often regarded as the most important contributors to BNF in the upper ocean (Carpenter, 1972; Phlips et al., 1986; Capone et al., 1997; Montoya et al., 2004). However, it seems heterotrophic diazotrophs may have an important association with decomposing Sargassum and Macrocystis (Hamersley et al., 2015), but with varying degrees of contribution to BNF. The possibility for DMAs to occur within numerous macroalgal detrital systems, as discussed previously, may provide an unexplored niche for heterotrophic $\mathrm{N}$ fixers, requiring additional investigation.

\section{Impact of Labile Carbon on Nitrogenase Activity}

The concentrations of various organic molecules (e.g., alginates, phenols, total carbohydrates, proteins, reducing sugars, etc.) generally decline throughout macrophyte decomposition, resembling trends in loss of biomass throughout the three stages of decomposition (Cundell et al., 1979; Buchsbaum et al., 1991; Sathe-Pathak et al., 1993). Generally, rapid buildup in microbial biomass, observed after leaching of organic compounds during the first phase of decomposition, begins to decline as the detritus enters a more refractory phase, suggesting that the utilization of labile carbon is an important controlling factor for sustaining microbial populations during macrophyte decomposition (Cundell et al., 1979; Sathe-Pathak et al., 1993). Considering the high energetic cost of BNF and assuming the diazotrophic population is following similar changes in biomass to the whole microbial community, it is likely that the availability of various labile organic compounds may also have influenced nitrogenase activity associated with aging S. horneri and S. palmeri detritus.

During the first phase of $S$. horneri decomposition ( days $0-5)$, the availability of labile carbon may have been limiting BNF in the dark, and thus, even relatively lower $(100 \mu \mathrm{M})$ concentrations of glucose and mannitol were able to stimulate BNF on day 0 (Figure 3A). However, 10x higher (1 mM) glucose and mannitol additions did not significantly stimulate BNF throughout the second phase of decomposition ( days $5-14$ ), suggesting that availability of labile organic compounds during this phase were sufficient to support diazotrophic activity (Figures 3A,B). Interestingly, these same amendments in both the light and dark were able to stimulate diazotrophic activity, by $\sim 5$ - to 15 -fold, associated with the more recalcitrant $S$. horneri detritus remaining on day 21 (Figures $3 \mathbf{A}, \mathbf{B}$ ). While this suggests that labile carbon may also be limiting BNF at the end of decomposition, these elevated BNF rates stimulated by carbon additions were relatively lower than control BNF rates observed throughout the second phase of decomposition (i.e., days 5, 11). This indicates a potential decrease in diazotrophic population and activity by the end of decomposition. In contrast, carbon additions routinely stimulated BNF rates, particularly in the dark, throughout the different stages of $S$. palmeri decomposition (Figures 3C,D). This suggests that the release of organic compounds throughout $S$. palmeri decomposition was not as accessible to the diazotrophic community, resulting in labile carbon limitation for $\mathrm{N}$ fixers associated with the aging $\mathrm{S}$. palmeri detritus.

\section{Sulfate Reducing Diazotrophs}

While there have been several studies reporting sulfate reduction associated with sediments in different macrophyte systems such as salt marshes (Hines et al., 1989), seagrasses (Capone, 1982; Blaabjerg and Finster, 1998), and mangroves (Kristensen et al., 1994), there are not many investigations looking directly at sulfate reduction associated with degrading macroalgae. Interestingly, a few studies have reported increased sulfate reduction associated with the decomposition of the green macroalga, Ulva lactuca (Nedergaard et al., 2002; Lomstein et al., 2006). Nedergaard et al. (2002) even found sulfate reduction to be more prominent with macroalgal-associated sulfate reducers than sediment associated and free living sulfate reducers during the degradation of $U$. lactuca, suggesting that the presence of sulfate reducers in macroalgal detrital systems may not be that uncommon. In this study, higher rates of BNF in the dark and possible microaerobic niches associated with $S$. horneri detritus suggested a potential role for sulfate reducers, which generally are thought to be active in anoxic zones (Canfield et al., 2010) but have also been observed in ostensibly oxic environments (Canfield and Marais, 1991).

Fulweiler et al. (2015) have demonstrated that the active microbial community can change by the end of an $\mathrm{AR}$ incubation and more specifically, the presence of $\mathrm{C}_{2} \mathrm{H}_{2}$, which is known to inhibit methanogens (Oremland and Capone, 1988), can result in up or down regulation of sulfur/sulfate reducers. However, despite potential changes induced by the presence $\mathrm{C}_{2} \mathrm{H}_{2}$, the use of sodium molybdate additions, a known inhibitor of sulfate reducers (Oremland and Capone, 1988), in the 2017 S. horneri decomposition experiment yielded reproducible instances of significantly reduced nitrogenase activity ( $\sim 53-98 \%$ inhibition). This suggests that sulfate reducers can contribute to BNF and at times, dominate the diazotrophic community in these detrital systems. Surprisingly, this translated into noticeable changes with 
the C:N ratio associated with $S$. horneri detritus, discussed below. Although sulfate reduction rates were not directly measured in this study, increasing inhibition of nitrogenase activity (up to $98 \%$ by day 12) throughout decomposition suggests that increasing sulfate reduction may also be associated with aging S. horneri detritus as observed by Nedergaard et al. (2002) and Lomstein et al. (2006) with U. lactuca decomposition. This suggests that sulfate reducers might be playing an important role in the breakdown of the more recalcitrant macroalgal detritus left toward the latter phases of macroalgal decomposition.

\section{Imprint of BNF on S. horneri Detritus}

A common observation with aging macrophyte detritus is the decrease in C: $\mathrm{N}$ ratio throughout decomposition which has been linked, with varying extent, to the associated diazotrophic activity (Cundell et al., 1979; Kenworthy and Thayer, 1984; Kenworthy et al., 1987). Additionally, there have also been several studies that directly link BNF observed in these marine detrital systems to $\mathrm{N}$ immobilization of the aging detritus, highlighting the importance of diazotrophs in marine detrital food chains (Van der Valk and Attiwill, 1984; Woitchik et al., 1997; Pelegri and Twilley, 1998). Not surprisingly, this trend of decreasing C:N ratio (observed in this study with the 2017 S. horneri decomposition experiment, Figure 5C) has also been reported on several accounts with aging macroalgal detritus but not linked directly to BNF and instead, generally attributed to the buildup of microbial biomass (Smith and Foreman, 1984; Rieper-Kirchner, 1989; Duggins and Eckman, 1997; Banta et al., 2004). Alternatively, Rice (1982) argue that increases in detrital $\mathrm{N}$ cannot be fully accounted for by microbial protein but rather, depend more on the accumulation of non-labile $\mathrm{N}$, which has also been suggested by others (Robinson et al., 1982; Smith and Foreman, 1984). In this study, changes in the $\% \mathrm{C}, \% \mathrm{~N}, \mathrm{C}: \mathrm{N}$ ratio, and $\delta^{15} \mathrm{~N}$ alongside $\mathrm{BNF}$ rates from the second $S$. horneri decomposition experiment (Figures 4A,B, 5A-D) highlight the potential influence that diazotrophs may have on aging macroalgal detritus.

For instance, the largest decrease in $\mathrm{C}: \mathrm{N}$ ratio, taking place over the first few days of decomposition, is accompanied by relatively little change in $\% \mathrm{C}$ and is most likely driven by the steep increase in $\% \mathrm{~N}$ (Figures $\mathbf{5 A - C}$ ). The BNF rates associated with dark and light control incubations on day 3 can account for $\sim 5$ and $11 \%$, respectively, of the observed $\mathrm{N}$ immobilization. On the contrary, parallel dark and light sodium molybdate incubations, where 66 and $88 \%$ of the nitrogenase activity was inhibited (Figures 4A,B), resulted in PID that were $\sim 24$ and $28 \%$ more depleted in $\mathrm{N}$, respectively, than the control treatments (Figures 5B,C). The sharpest decrease in $\delta^{15} \mathrm{~N}$ of FD from $12.2 \%$ to $10.7 \%$ also occurred during this period (Figure 5D), further supporting that BNF may be playing a direct role in influencing the changes associated with $S$. horneri detrital N. On day 8, BNF can account for $\sim 2$ and $1 \%$ of the observed increase in $\mathrm{N}$ with PID from dark and light control incubations. Interestingly, sodium molybdate amendments did not inhibit nitrogenase activity in the light (Figure 4B) and the corresponding BNF accounted for $4 \%$ of the $\mathrm{N}$ immobilization. These relatively low contributions suggest that BNF was not playing a significant role in $\mathrm{N}$ immobilization during this period.
Instead, potential increases in microbial biomass, characteristic of the second phase of decomposition, or retention of refractory $\mathrm{N}$ in aging $S$. horneri detritus might account for much of the $\mathrm{N}$ immobilization. Nonetheless, the lack of nitrogenase inhibition by sodium molybdate on day 8 resulted in a $\sim 11 \%$ more $\mathrm{N}$ enriched PID in the light than when BNF was strongly inhibited, 69\%, in the dark (Figure 5B). Similarly, strong inhibition of nitrogenase activity on day 12, 95-98\%, by sodium molybdate treatments (Figures 4A,B) resulted in PID that was $\sim 11-33 \%$ more $\mathrm{N}$ depleted (Figure $5 \mathrm{~B}$ ). This, alongside a smaller difference in $\mathrm{C}$ content between light and dark molybdate incubations, results in a significantly higher $\mathrm{C}: \mathrm{N}$ ratio for PID when $\mathrm{BNF}$ is inhibited, suggesting that BNF could still indirectly be influencing the nutritional quality of the macroalgal detritus. While a few studies have suggested BNF as a potential source of $\mathrm{N}$ enrichment (Hill and McQuaid, 2009; Hamersley et al., 2015), our results provide direct evidence for how BNF, or therein lack of, can influence the nutritional quality of the aging $S$. horneri detritus.

\section{CONCLUSION}

Investigating the role of diazotrophs with S. horneri throughout its life cycle has provided insight into the relevance of BNF with regard to the success of this globally relevant macroalga in a nonnative ecosystem. Our findings suggest, at least during periods of $\mathrm{N}$ deficiency, that $\mathrm{BNF}$ can potentially provide significant amounts of fixed $\mathrm{N}$ to macroalgae and heterotrophic BNF associated with living macroalgae may be more significant than what is currently thought. Higher BNF rates observed with decomposing Sargassum in this study, which has also been reported in the past with pelagic Sargassum (Hanson, 1977; Phlips et al., 1986), suggests that DMAs with decomposing Sargassum species may be a global occurrence. Moreover, several studies reporting higher BNF activity associated with other senescent brown (Hamersley et al., 2015) and green (Zuberer and Silver, 1978) macroalgae further suggest that DMAs with aging macroalgal detritus may not be a rare phenomenon. Macroalgae such as $S$. horneri may provide a niche for BNF and these DMAs may ultimately allow for a more efficient decomposition of a large reservoir of organic material. Currently, the macroalgal detrital food web remains a vastly unexplored niche for $\mathrm{N}$ fixers. Our findings suggest that heterotrophic $\mathrm{N}$ fixers and sulfate reducing diazotrophs may be important members of macroalgal detrital diazotrophic communities. As most macroalgal production ultimately enters the detrital food web, future studies investigating DMAs with decomposing macroalgae are necessary to elucidate the role of BNF in these detrital systems.

\section{AUTHOR CONTRIBUTIONS}

YR, MM, and DC designed the research. YR conducted the research, and analyzed and synthesized the data. YR and DC wrote the manuscript. 


\section{ACKNOWLEDGMENTS}

We would like to thank the USC Wrigley Marine Science Center (WMSC) and summer Wrigley/Victoria J. Bertics Fellowships (2016-2017) for supporting this research and the WMSC staff, especially Lauren Czarnecki Oudin and Kellie Spafford, for all their accommodations. We want to thank the participants from past Research Experience for Undergraduates programs (NSF Award OCE-1559941), Amanda DeLiberto, Shannon Matzke, Camille Vieira, and Taylor Dillon, for all their contribution. We also want to thank all members of the Capone lab, especially

\section{REFERENCES}

Abé, H., Komatsu, T., Kokubu, Y., Natheer, A., Rothausler, E. A., Shishido, H., et al. (2013). Invertebrate fauna associated with floating Sargassum horneri (Fucales: Sargassaceae) in the East China Sea. Species Divers. 18, 75-85. doi: 10.12782/sd.18.1.075

Banta, G. T., Pedersen, M. F., and Nielsen, S. L. (2004). “Decomposition of marine primary producers: consequences for nutrient recycling and retention in coastal ecosystems," in Estuarine Nutrient Cycling: The Influence of Primary Producers, eds S. L. Nielsen, G. T. Banta, and M. F. Pedersen (Dordrecht: Kluwer Academic Publishers), 187-216.

Blaabjerg, V., and Finster, K. (1998). Sulphate reduction associated with roots and rhizomes of the marine macrophyte Zostera marina. Aquat. Microb. Ecol. 15, 311-314. doi: 10.3354/ame015311

Breitbarth, E., Mills, M. M., Friedrichs, G., and Laroche, J. (2004). The Bunsen gas solubility coefficient of ethylene as a function of temperature and salinity and its importance for nitrogen fixation assays. Limnol. Oceanogr. Methods 2, 282-288. doi: 10.4319/lom.2004.2.282

Buchsbaum, R., Valiela, I., Swain, T., Dzierzeski, M., and Allen, S. (1991). Available and refractory nitrogen in detritus of coastal vascular plants and macroalgae. Mar. Ecol. Prog. Ser. 72, 131-143. doi: 10.3354/meps072131

Butler, J. N., and Stoner, A. W. (1984). Pelagic Sargassum: has its biomass changed in the last 50 years? Deep Sea Res. Part A Oceanogr. Res. Pap. 31, 1259-1264. doi: 10.1016/0198-0149(84)90061-X

Canfield, D. E., and Marais, D. J. D. (1991). Aerobic sulfate reduction in microbial mats author. Science (80-) 251, 1471-1473. doi: 10.1126/science.11538266

Canfield, D. E., Stewart, F. J., Thamdrup, B., De Brabandere, L., Dalsgaard, T., Delong, E. F., et al. (2010). A cryptic sulfur cycle in oxygen minimum zone waters off the Chilean coast. Science (80-) 330, 1375-1378. doi: 10.1126/science. 1196889

Capone, D. (1982). Nitrogen fixation(acetylene reduction) by rhizosphere sediments of the eelgrass Zostera marina. Mar. Ecol. Prog. Ser. 10, 67-75. doi: 10.3354/meps010067

Capone, D. G. (1977). "N2(C2H2) fixation by macroalgal epiphytes," in Proceedings Third International Coral Reef Symposium, Miami, FL, 338-342.

Capone, D. G. (1993). "Determination of nitrogenase activity in aquatic samples using the acetylene reduction procedure," in Handbook of Methods in Aquatic Microbial Ecology, eds P. F. Kemp, J. J. Cole, B. F. Sherr, and E. B. Sherr (Boca Raton, FL: Lewis), 621-631.

Capone, D. G. (2001). Marine nitrogen fixation: what's the fuss? Curr. Opin. Microbiol. 4, 341-348. doi: 10.1016/S1369-5274(00)00215-0

Capone, D. G., and Budin, J. M. (1982). Nitrogen fixation associated with rinsed roots and rhizomes of the eelgrass Zostera marina. Plant Physiol. 70, 1601-1604. doi: 10.1104/pp.70.6.1601

Capone, D. G., Taylor, D. L., and Taylor, B. F. (1977). Nitrogen fixation (acetylene reduction) associated with macroalgae in a coral-reef community in the bahamas. Mar. Biol. 40, 29-32. doi: 10.1007/BF00390624

Capone, D. G., Zehr, J. P., Paerl, H. W., Bergman, B., and Carpenter, E. J. (1997). Trichodesmium, a globally significant marine cyanobacterium. Science (80). 276, 1221-1229. doi: 10.1126/science.276.5316.1221

Carpenter, E. (1972). Nitrogen fixation by a blue-green epiphyte on pelagic Sargassum. Science (80-) 178, 1207-1209. doi: 10.1126/science.178.4066.1207
Weimin Deng, Miguel Rincon, Suryia Tanjasiri, Chrystal Li, Jill Sohm, and Troy Gunderson, for their help. We thank the Ziebis lab, especially Bingran Cheng, for help with $\mathrm{O}_{2}$ measurements.

\section{SUPPLEMENTARY MATERIAL}

The Supplementary Material for this article can be found online at: https://www.frontiersin.org/articles/10.3389/fmicb. 2018.03127/full\#supplementary-material

Caselle, J. E., Davis, K., and Marks, L. M. (2018). Marine management affects the invasion success of a non-native species in a temperate reef system in California, USA. Ecol. Lett. 21, 43-53. doi: 10.1111/ele.12869

Chapman, A. R. O., and Craigie, J. S. (1977). Seasonal growth in Laminaria longicruris: relations with dissolved inorganic nutrients and internal reserves of nitrogen. Mar. Biol. 40, 197-205. doi: 10.1007/BF00390875

Choi, H. G., Lee, K. H., Il Yoo, H., Kang, P. J., Kim, Y. S., and Nam, K. W. (2008). Physiological differences in the growth of Sargassum horneri between the germling and adult stages. J. Appl. Phycol. 20, 729-735. doi: 10.1007/s10811007-9281-5

Coston-Clements, L., Settle, L. R., Hoss, D. E., and Cross, F. A. (1991). Utilization of the Sargassum habitat by Marine Invertebrates and Vertebrates - A Review/L. Coston-Clements, L.R. Settle, D.E. Hoss, and F.A. Cross. Beaufort, NC: Beaufort Laboratory, 1-32.

Cruz-Trejo, G. I., Ibarra-Obando, S. E., Aguilar-Rosas, L. E., Poumian-Tapia, M., Solana-Arellano, E., and Cruz-Trejo, G. I. (2015). Presence of Sargassum horneri at todos santos bay, baja california, mexico: its effects on the local macroalgae community. Am. J. Plant Sci. 6, 2693-2707. doi: 10.4236/ajps.2015.617271

Cundell, A. M., Brown, M. S., Stanford, R., and Mitchell, R. (1979). Microbial degradation of Rhizophora mangle leaves immersed in the sea. Estuar. Coast. Mar. Sci. 9, 281-286. doi: 10.1016/0302-3524(79)90041-0

Duarte, C. M., Middelburg, J. J., and Caraco, N. (2005). Major role of marine vegetation on the oceanic carbon cycle. Biogeosciences 2, 1-8. doi: 10.5194/bg2-1-2005

Duggins, D. O., and Eckman, J. E. (1997). Is kelp detritus a good food for suspension feeders? Effects of kelp species, age and secondary metabolites. Mar. Biol. 128, 489-495. doi: 10.1007/s002270050115

Farnelid, H., Bentzon-Tilia, M., Andersson, A. F., Bertilsson, S., Jost, G., Labrenz, M., et al. (2013). Active nitrogen-fixing heterotrophic bacteria at and below the chemocline of the central Baltic Sea. ISME J. 7, 1413-1423. doi: 10.1038/ismej.2013.26

Fay, P. (1992). Oxygen relations of nitrogen fixation in cyanobacteria. Microbiol. Rev. 56, 340-373. doi: 10.1016/S0168-6445(98)00012-6

Flett, R. J., Hamilton, R. D., and Campbell, N. E. R. (1976). Aquatic acetylenereduction techniques: solutions to several problems. Can. J. Microbiol. 22, 43-51. doi: 10.1139/m76-006

France, R., Holmquist, J., Chandler, M., and Cattaneo, A. (1998). d15N evidence for nitrogen fixation associated with macroalgae from a seagrass - Mangrove Coral reef system. Mar. Ecol. Prog. Ser. 167, 297-299. doi: 10.3354/meps 167297

Fujita, R., Wheeler, P., and Edwards, R. (1989). Assessment of macroalgal nitrogen limitation in a seasonal upwelling region. Mar. Ecol. Prog. Ser. 53, 293-303. doi: 10.3354/meps053293

Fulweiler, R. W., Heiss, E. M., Rogener, M. K., Newell, S. E., LeCleir, G. R. Kortebein, S. M., et al. (2015). Examining the impact of acetylene on N-fixation and the active sediment microbial community. Front. Microbiol. 6:418. doi: 10.3389/fmicb.2015.00418

Gagné, J. A., Mann, K. H., and Chapman, A. R. O. (1982). Seasonal patterns of growth and storage in Laminaria longicruris in relation to different patterns of availability of nitrogen in the water. Mar. Biol. 69, 91-101. doi: 10.1007/ BF00396965

Gao, K., and Hua, W. (1997). In situ growth rates of Sargassum horneri (Fucales, Phaeophyta)*. Phycol. Res. 45, 55-57. doi: 10.1111/j.1440-1835.1997.tb00062.x 
Gerard, V. A., Dunham, S. E., and Rosenberg, G. (1990). Nitrogen-fixation by cyanobacteria associated with Codium fragile (Chlorophyta): environmental effects and transfer of fixed nitrogen. Mar. Biol. 105, 1-8. doi: 10.1007/ BF01344264

Godshalk, G. L., and Wetzel, R. G. (1978). Decomposition of aquatic angiosperms. III. Zostera marina L. and a conceptual model of decomposition. Aquat. Bot. 5, 329-354. doi: 10.1016/0304-3770(78)90075-X

Goecke, F., Labes, A., Wiese, J., and Imhoff, J. F. (2010). Review chemical interactions between Marine macroalgae and bacteria. Mar. Ecol. Prog. Ser. 409, 267-300. doi: 10.3354/meps08607

Goldner, L. L. (1980). Nitrogen fixation (acetylene reduction) in shallow water Bahamian environments. Bull. Mar. Sci. 30, 444-453.

Gotto, J. W., and Taylor, B. F. (1976). N(2) fixation associated with decaying leaves of the red mangrove (Rhizophora mangle). Appl. Environ. Microbiol. 31, 781-783.

Graham, M. H., Vásquez, J. A., and Buschmann, A. H. (2007). Global ecology of the giant kelp macrocystis?: from ecotypes to ecosystems. Oceanogr. Mar. Biol. 45, 39-88. doi: 10.1201/9781420050943.ch2

Hamersley, M. R., Sohm, J. A., Burns, J. A., and Capone, D. G. (2015). Nitrogen fixation associated with the decomposition of the giant kelp Macrocystis pyrifera. Aquat. Bot. 125, 57-63. doi: 10.1016/j.aquabot.2015.05.003

Hamersley, M. R., Turk, K. A., Leinweber, A., Gruber, N., Zehr, J. P., Gunderson, T., et al. (2011). Nitrogen fixation within the water column associated with two hypoxic basins in the Southern California Bight. Aquat. Microb. Ecol. 63, 193-205. doi: 10.3354/ame01494

Hanisak, M. D. (1983). The nitrogen relationships of marine macroalgae. Nitrogen Mar. Environ. 20, 699-730. doi: 10.1016/B978-0-12-160280-2.50027-4

Hanson, R. B. (1977). Pelagic sargassum community metabolism: carbon and nitrogen. J. Exp. Mar. Biol. Ecol. 29, 107-118. doi: 10.1016/0022-0981(77) 90042-9

Head, W. D., and Carpenter, E. J. (1975). Nitrogen fixation associated with the marine macroalga Codium fragile. Limnol. Oceanogr. 20, 815-823. doi: 10.4319/ lo.1975.20.5.0815

Hill, J. M., and McQuaid, C. D. (2009). Variability in the fractionation of stable isotopes during degradation of two intertidal red algae. Estuar. Coast. Shelf Sci. 82, 397-405. doi: 10.1016/j.ecss.2009.02.001

Hines, M. E., Knollmeyer, S. L., Tugel, J. B., Limnology, S., and May, N. (1989). Sulfate reduction and other sedimentary biogeochemistry in a northern New England salt marsh. Limnol. Oceanogr. 34, 578-590. doi: 10.4319/lo.1989.34.3. 0578

Howarth, R. W., Marino, R., Lane, J., and Cole, J. J. (1988). Nitrogen fixation in freshwater,estuarine, and marine ecosystems. 1. rates and importance. Limnol. Oceanogr. 33, 669-687. doi: 10.4319/lo.1988.33.4_part_2.0669

Hunter, R. D. (1976). Change in carbon and nitrogen content during decomposition of three macrophytes in freshwater and marine environments. Hydrobiologia 51, 119-128. doi: 10.1007/BF00009827

Ingólfsson, A. (2000). Colonization of floating seaweed by pelagic and sub tidal benthic. Hydrobiologia 440, 181-189. doi: 10.1023/A:1004119126869

Kaplanis, N. J., Harris, J. L., and Smith, J. E. (2016). Distribtuion patterns of the non-native seaweeds Sargassum horneri (Turner) C. Agardh and Undaria pinnatifida (Harvey) suringar on the San Diego and Pacific coast of North America. Aquat. Invasions 11, 111-124. doi: 10.3391/ai.2016.11.2.01

Keith, S. A., Kerswell, A. P., and Connolly, S. R. (2014). Global diversity of marine macroalgae: environmental conditions explain less variation in the tropics. Glob. Ecol. Biogeogr. 23, 517-529. doi: 10.1111/geb.12132

Kenworthy, W. J., Currin, C., Smith, G., and Thayer, G. (1987). The abundance, biomass and acetylene reduction activity of bacteria associated with decomposing rhizomes of two seagrasses, Zostera marina and Thalassia testudinum. Aquat. Bot. 27, 97-119. doi: 10.1016/0304-3770(87)90088-X

Kenworthy, W. J., and Thayer, G. W. (1984). Production and decomposition of the roots and rhizomes of seagrass, Zostera marina and Thalassian testudinum, in temperate and subtropical marine ecosytems. Bull. Mar. Sci. 35, 364-379.

Kokubu, Y., Komatsu, T., Ito, M., Hattori, T., and Narimatsu, Y. (2012). Biomass of marine macrophyte debris on the ocean floor southeast of Hokkaido Island adjusted by experimental catch efficiency estimates. La mer 50, 11-21.

Komatsu, T. (1989). Day-night reversion in the horizontal distributions of dissolved oxygen content and $\mathrm{pH}$ in a sargassum forest. J. Oceanogr. Soc. Jpn. 45, 106-115. doi: 10.1007/BF02108884
Komatsu, T., Matsunaga, D., Mikami, A., Sagawa, T., Boisnier, E., Tatsukawa, K., et al. (2008). Abundance of drifting seaweeds in eastern East China Sea. J. Appl. Phycol. 20, 801-809. doi: 10.1007/s10811-007-9302-4

Komatsu, T., Tatsukawa, K., Filippi, J. B., Sagawa, T., Matsunaga, D., Mikami, A., et al. (2007). Distribution of drifting seaweeds in eastern East China Sea. J. Mar. Syst. 67, 245-252. doi: 10.1007/s10811-007-9302-4

Krause-Jensen, D., and Duarte, C. M. (2016). Substantial role of macroalgae in marine carbon sequestration. Nat. Geosci. 9, 737-742. doi: 10.1038/ngeo2790

Kristensen, E., King, G. M., Holmer, M., Banta, G. T., Jensen, M. H., Hansen, K., et al. (1994). Sulfate reduction, acetate turnover and carbon metabolism in sediments of the Ao Nam Bor Mangrove, Phuket, Thailand. Mar. Ecol. Prog. Ser. 109, 245-256. doi: 10.3354/meps111245

Lapointe, B. E. (1997). Nutrient thresholds for bottom-up control of macroalgal blooms on coral reefs in Jamaica and southeast Florida. Limnol. Oceanogr. 42, 1119-1131. doi: 10.4319/lo.1997.42.5_part_2.1119

Lapointe, B. E., West, L. E., Sutton, T. T., and Hu, C. (2014). Ryther revisited: nutrient excretions by fishes enhance productivity of pelagic Sargassum in the western North Atlantic Ocean. J. Exp. Mar. Biol. Ecol. 458, 46-56. doi: 10.1016/ j.jembe.2014.05.002

Larned, S. T. (1998). Nitrogen- versus phosphorus-limited growth and sources of nutrients for coral reef macroalgae. Mar. Biol. 132, 409-421. doi: 10.1007/ s002270050407

Lomstein, B. A., Guldberg, L. B., Neubauer, A. T. A., Hansen, J., Donnelly, A., Herbert, R. A., et al. (2006). Benthic decomposition of Ulva lactuca: a controlled laboratory experiment. Aquat. Bot. 85, 271-281. doi: 10.1016/j.aquabot.2006.05. 006

Mann, K. H. (1973). Seaweeds: their productivity and strategy for growth. Science (80-) 182, 975-981. doi: 10.1002/9780470114735.hawley00624

Marks, L., Salinas-Ruiz, P., Reed, D., Holbrook, S., Culver, C., Engle, J., et al. (2015). Range expansion of a non-native, invasive macroalga Sargassum horneri (Turner) C. Agardh, 1820 in the eastern Pacific. BioInvasions Rec. 4, 243-248. doi: 10.3391/bir.2015.4.4.02

McCook, L. J. (1997). Effects of herbivory on zonation of Sargassum spp. within fringing reefs of the central great barrier reef. Mar. Biol. 129, 713-722. doi: $10.1007 / \mathrm{s} 002270050214$

Middelburg, J. J., and Levin, L. A. (2009). Coastal hypoxia and sediment biogeochemistry. Biogeosciences 6, 1273-1293. doi: 10.5194/bg-6-1273-2009

Miller, K. A., Engle, J. M., Uwai, S., and Kawai, H. (2007). First report of the Asian seaweed Sargassum filicinum Harvey (Fucales) in California, USA. Biol. Invasions 9, 609-613. doi: 10.1007/s10530-006-9060-2

Mizuno, S., Ajisaka, T., Lahbib, S., Kokubu, Y., Alabsi, M. N., and Komatsu, T. (2014). Spatial distributions of floating seaweeds in the East China Sea from late winter to early spring. J. Appl. Phycol. 26, 1159-1167. doi: 10.1007/s10811013-0139-8

Montoya, J. P., Holl, C. M., Zehr, J. P., Hansen, A., Villareal, T. A., and Capone, D. G. (2004). High rates of N2 fixation by unicellular diazotrophs in the oligotrophic Pacific Ocean. Nature 430, 1027-1031. doi: 10.1038/nature02744.1

Nedergaard, R. I., Risgaard-Petersen, N., and Finster, K. (2002). The importance of sulfate reduction associated with Ulva lactuca thalli during decomposition: a mesocosm experiment. J. Exp. Mar. Biol. Ecol. 275, 15-29. doi: 10.1016/S00220981(02)00211-3

O'Donohue, M. J., Moriarty, D. J. W., and Rae, I. C. M. (1991). Nitrogen fixation in sediments and the rhizosphere of the seagrass Zostera capricorni. Microb. Ecol. 22, 53-64. doi: 10.1007/BF02540212

Odintsov, V. S. (1992). Nitrogen fixing activity associated with subtidal macrophytes of the Seychelles Islands. Atoll Res. Bull. 372, 1-4. doi: 10.5479/ si.00775630.372.1

Oremland, R., and Capone, D. G. (1988). Advances in Microbial Ecology, 10th Edn, ed. K. C Marshall. New York, NY: Plenum Publishing Corporation. doi: 10.1007/978-1-4615-9412-3

Pacheco-Ruíz, I., Zertuche-González, J. A., Chee-Barragán, A., and BlancoBetancourt, R. (1998). Distribution and quantification of sargassum beds along the west coast of the gulf of California, Mexico. Bot. Mar. 41, 203-208. doi: 10.1515/botm.1998.41.1-6.203

Paerl, H. W., Bebout, B. M., and Prufert, L. E. (1989). Bacterial associations with marine Oscillatoria sp. (Trichodesmium sp.) populations: ecophysiological implications. J. Phycol. 25, 773-784. doi: 10.1111/j.0022-3646.1989. 00773.x 
Pedersen, M. F., and Borum, J. (1996). Nutrient control of algal growth in estuarine waters. Nutrient limitation and the importance of nitrogen requirements. Mar. Ecol. Prog. Ser. 142, 261-272. doi: 10.3354/meps142261

Pelegri, S. P., and Twilley, R. R. (1998). Heterotrophic nitrogen fixation (acetylene reduction) during leaf-litter decomposition of two mangrove species from South Florida, USA. Mar. Biol. 13, 53-61. doi: 10.1007/s002270050296

Phlips, E. J., Willis, M., and Verchick, A. (1986). Aspects of nitrogen fixation in Sargassum communities off the coast of Florida. J. Exp. Mar. Biol. Ecol. 102, 99-119. doi: 10.1016/0022-0981(86)90170-X

Rice, D. L. (1982). The detritus nitrogen problem: new observations and perspectives from organic Geochemistry. Mar. Ecol. Prog. Ser. 9, 153-162. doi: 10.3354/meps009153

Rice, D. L., and Hanson, R. B. (1984). A kinetic model for detritus nitrogen: role of the associated bacteria in nitrogen accumulation. Bull. Mar. Sci. 35, 326-340.

Rieper-Kirchner, M. (1989). Microbial degradation of North Sea macroalgae: field and laboratory studies. Bot. Mar. 32, 241-252. doi: 10.1515/botm.1989.32.3.241

Robinson, J. D., Mann, K. H., and Novitsky, J. A. (1982). Conversion of the particulate fraction of seaweed detritus to bacterial biomass. Limnol. Oceanogr. 27, 1072-1079. doi: 10.4319/lo.1982.27.6.1072

Rosenberg, G., and Paerl, H. W. (1981). Nitrogen-fixation by blue-green-algae associated with the siphonous green seaweed codium-decorticatum - Effects on ammonium uptake. Mar. Biol. 61, 151-158. doi: 10.1007/BF00386654

Sathe-Pathak, V., Raghukumar, S., Raghukumar, C., and Sharma, S. (1993). Thraustochytrid and fungal component of marine detritus. I-Field studies on decomposition of the brown alga Sargassum cinereum. J. Ag. Indian J. Mar. Sci. $22,159-167$.

Schaffelke, B., and Klumpp, D. W. (1997). Biomass and productivity of tropical macroalgae on three nearshore fringing reefs in the central Great Barrier Reef, Australia. Bot. Mar. 40, 373-383. doi: 10.1515/botm.1997.40.1-6.373

Smith, B. D., and Foreman, R. E. (1984). An assessment of seaweed decomposition within a southern Strait of Georgia seaweed community. Mar. Biol. 205, 197205. doi: 10.1007/BF00393005

Stæhr, P. A., Pedersen, M. F., Thomsen, M. S., Wernberg, T., and Krause-Jensen, D. (2000). Invasion of Sargassum muticum in Limfjorden (Denmark) and its possible impact on the indigenous macroalgal community. Mar. Ecol. Prog. Ser. 207, 79-88. doi: 10.3354/meps207079

Tenore, K. R., Hanson, R. B., Dornseif, B. E., and Wiederhold, C. N. (1979). The effect of organic nitrogen supplement on the utilization of different sources of detritus1. Limnol. Oceanogr. 24, 350-355. doi: 10.4319/lo.1979.24. 2.0350

Tilstra, A., Bednarz, V. N., Cardini, U., Van Hoytema, N., Al-Rshaidat, M. M. D., and Wild, C. (2017). Seasonality affects dinitrogen fixation associated with two common macroalgae from a coral reef in the northern Red Sea. Mar. Ecol. Prog. Ser. 575, 69-80. doi: 10.3354/meps 12206

Umezaki, I. (1984). Ecological studies of Sargassum horneri (Turner) C. Agardh in Obama Bay, Japan Sea. Bull. Jpn. Soc. Sci. Fish. 50, 1193-1200. doi: 10.1007/ BF02489559

Valiela, I., Mcclelland, J., Hauxwell, J., Behr, P. J., Hersh, D., and Foreman, K. (1997). Macroalgal blooms in shallow estuaries: controls and ecophysiological and ecosystem consequences. Limnol. Oceanogr. 42, 1105-1118. doi: 10.4319/ lo.1997.42.5_part_2.1105
Valiela, I., Teal, J. M., Allen, S. D., Van Etten, R., Goehringer, D., and Volkmann, S. (1985). Decomposition in salt marsh ecosystems: the phases and major factors affecting disappearance of above-ground organic matter. J. Exp. Mar. Bio. Ecol. 89, 29-54. doi: 10.1016/0022-0981(85)90080-2

Van der Valk, A. G., and Attiwill, P. M. (1984). Acetylene reduction in an Avicennia marina community in southern Australia. Aust. J. Bot. 32, 157-164. doi: 10. 1071/BT9840157

Wilcox, R. (2012a). "Multiple comparisons," in Modern Statistics for the Social and Behavioral Sciences (Boca Raton, FL: CRC Press), 565-620.

Wilcox, R. (2012b). "One-way ANOVA," in Modern Statistics for the Social and Behavioral Sciences (Boca Raton, FL: CRC Press), 427-481.

Wilcox, R. (2012c). "Two-way and three-way designs," in Modern Statistics for the Social and Behavioral Sciences (Boca Raton, FL: CRC Press), 483-525.

Williams, S. L. (1984). Decomposition of the tropical macroalga Caulerpa cupressoides (West) C. Agardh: field and laboratory studies. J. Exp. Mar. Bio. Ecol. 80, 109-124. doi: 10.1016/0022-0981(84)90007-8

Woitchik, A. F., Ohowa, B., Kazungu, J. M., Rao, R. G., Goeyens, L., and Dehairs, F. (1997). Nitrogen enrichment during decomposition of mangrove leaf litter in an east african coastal lagoon (kenya): relative importance of biological nitrogen fixation. Biogeochemistry 39, 15-35. doi: 10.1023/A:1005850032254

Yatsuya, K. (2008). Floating period of Sargassacean thalli estimated by the change in density. J. Appl. Phycol. 20, 797-800. doi: 10.1007/s10811-007-9293-1

Yoshida, G., Arima, S., and Terawaki, T. (1998). Growth and maturation of the "autumn-fruiting type" of Sargassum horneri (Fucales, Phaeophyta) and comparisons with the "spring-fruiting type." Phycol. Res. 46, 183-189. doi: 10.1111/j.1440-1835.1998.tb00112.x

Yoshida, G., Yoshikawa, K., and Terawaki, T. (2001). Growth and maturation of two populations of Sargassum horneri (Fucales, Phaeophyta) in Hiroshima Bay, the Seto Inland Sea. Fish. Sci. 67, 1023-1029. doi: 10.1046/j.1444-2906.2001. 00357.x

Zhang, S. Y., Wang, L., and Wang, W. D. (2008). Algal communities at Gouqi Island in the Zhoushan archipelago, China. J. Appl. Phycol. 20, 853-861. doi: 10.1007/s10811-008-9338-0

Zimmerman, R. C., and Kremer, J. N. (1984). Episodic nutrient supply to a kelp forest ecosystem in Southern California. J. Mar. Res. 42, 591-604. doi: 10.1357/ 002224084788506031

Zuberer, D. A., and Silver, W. S. (1978). Biological dinitrogen fixation (acetylene reduction ) associated with florida mangroves. Appl. Environ. Microbiol. 35, $567-575$.

Conflict of Interest Statement: The authors declare that the research was conducted in the absence of any commercial or financial relationships that could be construed as a potential conflict of interest.

Copyright (c) 2018 Raut, Morando and Capone. This is an open-access article distributed under the terms of the Creative Commons Attribution License (CC BY). The use, distribution or reproduction in other forums is permitted, provided the original author(s) and the copyright owner(s) are credited and that the original publication in this journal is cited, in accordance with accepted academic practice. No use, distribution or reproduction is permitted which does not comply with these terms. 